\title{
Partial immunoparesis contributes to risk of early infections in patients with multiple myeloma
}

\author{
Weimin Huang, Xiaolei Wei, Qi Wei, Yongqiang Wei, Ru Feng \\ Department of Hematology, Nanfang Hospital, Southern Medical University, Guangzhou, China \\ Contributions: (I) Conception and design: R Feng, Y Wei; (II) Administrative support: R Feng, Y Wei; (III) Provision of study materials or patients: \\ R Feng, Y Wei; (IV) Collection and assembly of data: W Huang, X Wei, Q Wei; (V) Data analysis and interpretation: W Huang, R Feng; \\ (VI) Manuscript writing: All authors; (VII) Final approval of manuscript: All authors. \\ Correspondence to: Ru Feng. Department of Hematology, Nanfang Hospital, Southern Medical University, Guangzhou 510515, China. \\ Email: ruth1626@hotmail.com.
}

Background: Partial immunoparesis, which means at least two suppressed uninvolved immunoglobulins (Igs), had been reported to be associated with poor prognosis in patients with multiple myeloma (MM), but the impact on early infections remains unknown. The purpose of our study was to determine the prognostic implications of partial immunoparesis on early grade $\geq 3$ infections in patients with MM.

Methods: Herein we retrospectively analyzed the clinical data of 123 MM patients between 2012 and 2020 at Nanfang Hospital. All patients received bortezomib-based regimens. The relationship between early grade $\geq 3$ infections and partial immunoparesis was investigated using Cox regression analysis.

Results: Our data showed partial immunoapresis was found in 63\% MM patients. Partial immunoparesis was significantly related to elevated beta-2-microglobulin (B2M), decreased estimated glomerular filtration rate (eGFR) and progressive international staging system (ISS) stage $(\mathrm{P}<0.05)$. Especially, univariate Cox regression analysis showed partial immunoparesis was significantly correlated with early grade $\geq 3$ infections $(\mathrm{P}=0.003)$. Moreover, multivariate Cox regression analysis showed partial immunoparesis was an independent significant prognostic factor for early grade $\geq 3$ infections [odds ratio $(\mathrm{OR})=3.048 ; 95 \%$ confidence interval (CI): 1.429-6.504; $\mathrm{P}=0.004]$. Furthermore, partial immunoapresis could improve the infection risk model built by Dumontet et al.

Conclusions: Our study showed that partial immunoparesis could predict early infections in patients with MM, which may be used to identify the high risk patients for infections and guide strategies for infection prevention.

Keywords: Immunoparesis; infection; multiple myeloma (MM); prediction

Submitted Aug 14, 2021. Accepted for publication Oct 22, 2021.

doi: $10.21037 /$ tcr-21-1627

View this article at: https://dx.doi.org/10.21037/tcr-21-1627

\section{Introduction}

The survival of multiple myeloma (MM) patients have been improved by the wide use of novel drugs and autologous stem cell transplantation (1). However, due to high incidence of early mortality (2-4), about $10 \%$ patients couldn't reap the benefits of them. Infections were the most common direct cause of early mortality, Augustson et al. (3) reported that infections contributed to almost $50 \%$ of early mortality and this rate was $65 \%$ in the study conducted by Hsu et al. (2). Meanwhile, infections also contribute to diseases progression through various mechanisms, such as production of interleukin-6 (5-7) and activation of Toll-like receptor signaling pathways $(8,9)$. Thus, infections impose a major threat to patients with $M M$ and there is an urgent clinical need for infections prediction and prevention.

Currently, two risk scoring system had been developed to predict the risk of early grade $\geq 3$ infections in patients with MM. Dumontet et al. (10) built a predict model including 
Eastern Cooperative Oncology Group-performance status (ECOG-PS), beta-2-microglobulin (B2M), lactate dehydrogenase (LDH) and hemoglobin levels. The high risk MM patients defined as 2 to 5 scores showed significantly higher rate of infections than the low risk patients $(24.0 \%$ vs. 7.0\%). However, the study only included patients treated with lenalidomide-based regimens. Valkovic et al. (11) had proposed the multiple myeloma index for risk of infection (MMIRI), with a sensitivity of $93.2 \%$ and specificity of $80.2 \%$. But this model was too complicated to be widely applied in clinical practice. It's urgent and necessary to explore new simple and useful markers for predicting infections in MM.

Normal immunoglobulins (Igs) play an important role in adaptive immune response to infections. In MM patients, normal plasma cells were inhibited by the rapidly proliferation of malignant plasma cells which causes immunoparesis and makes patients vulnerable to infections (12). Immunoparesis means at least one suppressed uninvolved Igs. Partial immunoparesis, which means at least two suppressed uninvolved Igs, had been shown to correlate with inferior clinical features and outcomes in MM patients (13-15). However, the correlation between immunoparesis and early infections in MM remained unclear. Herein we investigated the value of partial immunoparesis in predicting risk of early grade $\geq 3$ infection in $M M$ patients.

We present the following article in accordance with the STROBE reporting checklist (available at https://dx.doi. org/10.21037/tcr-21-1627).

\section{Methods}

We reviewed medical records from 123 newly diagnosed MM patients, according to IMWG criteria (16), between 2012 and 2020 at Nanfang Hospital. Patients diagnosed as solitary osseous MM, solitary extra-osseous MM and smoldering MM were excluded from this study. Patients that had biopsy proven organ involvement with lightchain (AL) amyloidosis at diagnosis or during the follow-up period were also excluded. All patients received bortezomibbased regimens. Sixty percent (74/123) received bortezomib and dexamethasone plus cyclophosphamide (VCD), 29\% (36/123) received bortezomib and dexamethasone plus thalidomide (VDT), 11\% (13/123) received bortezomib and dexamethasone plus doxorubicin (PAD). Among them, 10\% $(12 / 123)$ patients received autologous stem cell transplant (ASCT). Valacyclovir was taken as anti-viral prophylaxis. No antibiotic prophylaxis was used. The study was conducted in accordance with the Declaration of Helsinki (as revised in 2013). The current study protocol was approved by the Ethics Committee of Southern Medical University Nanfang Hospital, Guangzhou, China (No. NEFC-2020-R391). All patients gave written informed consent themselves prior to treatment allowing the use of their medical records for medical research.

ECOG-PS, hemoglobin, neutrophil, lymphocyte, B2M, albumin, $\mathrm{LDH}$, corrected calcium (cCa), C-reactive protein (CRP), N-terminal pro-B-type natriuretic peptide (NTproBNP), estimated glomerular filtration rate (eGFR) (17), international staging system (ISS), revised ISS (R-ISS) (18), and chromosomal abnormalities $[\mathrm{t}(4 ; 14), \mathrm{t}(11 ; 14), \mathrm{t}(14 ; 16)$, del17p13, del13q14, $\mathrm{t}(14 ; 20), \mathrm{t}(8 ; 14)]$ were assessed at diagnosis. Immunoparesis was defined as reduction of an uninvolved Ig below the lower limit of normal for our laboratory reference range, which for $\mathrm{IgG}$ was $<7 \mathrm{~g} / \mathrm{L}$, for IgA was $<0.7 \mathrm{~g} / \mathrm{L}$ and for IgM was $<0.4 \mathrm{~g} / \mathrm{L}$. Partial immunoparesis was defined as at least two suppressed uninvolved Igs. Hematologic adverse events (AEs) included neutropenia, thrombocytopenia. All AEs were graded according to National Cancer Institute Common Terminology Criteria for Adverse Events, version 5.0. Cumulative incidences of grade $\geq 3$ hematologic AEs, nonhematologic AEs were calculated from the time of treatment start until the date of first toxicity due to causes other than progression or death. Early grade $\geq 3$ infections correspond to the first grade $\geq 3$ infections during the first 4 months.

\section{Statistical analysis}

Statistical analysis was performed using the Statistical Package of Social Sciences version 22.0 for Windows. Continuous data were described with median and interquartile range (IQR). The $\chi^{2}$-test and Fisher's exact test were applied to assess the differences in nominal variables. Cumulative incidences were estimated by Kaplan-Meier method and compared using the log-rank test. Univariate and multivariate modeling were conducted by the Cox regression analysis. $\mathrm{P}<0.05$ was considered to be statistical significance.

\section{Results}

\section{Patient characteristics}

Data from a total of $123 \mathrm{MM}$ patients was retrospectively analyzed. The median follow-up period was 25 months 
(IQR: 16-40). The median age at diagnosis was 57 years (IQR: 51-64), which was similar to other recent studies of Chinese MM patients (19-22). According to ISS, $57 \%$ (70/123) patients were at stage III. Base on R-ISS, $21 \%$ (21/100) patients were at stage III. After induction, $81 \%$ $(100 / 123)$ patients acquired at least partial response and grade $\geq 3$ neutropenia was documented in $21 \%(26 / 123)$ patients.

Immunoparesis was found in $86 \%(106 / 123)$ patients and $63 \%(78 / 123)$ of them were resent with partial immunoparesis in our study. Patients with partial immunoparesis had significantly elevated B2M $(\mathrm{P}<0.001)$, lower eGFR $(\mathrm{P}=0.004)$ and advanced ISS stage $(\mathrm{P}<0.001)$. There were no differences in response, neutropenia between patients with and without partial immunoparesis (P>0.05). Among 12 transplanted patients, 10 of them had immunoparesis and 5 of them developed early grade $\geq 3$ infections. Clinical characteristics of patients according to partial immunoparesis were summarized in Table 1.

We also found the severity of immunosuppression was associated with early grade $\geq 3$ infections in patients with IgA and IgG MM (Table S1). In IgA MM patients, suppression of $\operatorname{IgM}(>0 \%$ and $>50 \%)$ and $\operatorname{IgG}(>25 \%)$ were significantly related to infections. In IgG MM patients, suppression of $\operatorname{IgA}(>0 \%$ and $>25 \%$ ) was also significantly related to infections. Although without significance, suppression of $\operatorname{IgM}(>50 \%)$ tended to have higher infection rates $(64 \%$ vs. $46 \%)$. However, no significant association between the severity of immunosuppression in light chain only MM.

\section{Partial immunoparesis and first early grade $\geq 3$ infections}

During the follow-up, $45 \%(55 / 123)$ patients presented at least one grade $\geq 3$ infection, the median time from diagnosis to the development of early grade $\geq 3$ infection was 22 days (IQR: 10-70). At the first 4 months, 39\% (48/123) patients presented at least one grade $\geq 3$ infection. Early grade $\geq 3$ infections and grade $\geq 3$ neutropenia at the time of infection were summarized in Table 2. The distribution of infections were similar to other study (23). Among them, pneumonia was the most common (70.8\%). The therapeutic regimens and grade $\geq 3$ neutropenia were shown in Table S2. Cause the regimens were all bortezomib-based, the incidences of infections were similar $(\mathrm{P}=0.056)$. No significant correlation between early grade $\geq 3$ neutropenia and early grade $\geq 3$ infections was found $(\mathrm{P}=0.249)$. Patients with early grade $\geq 3$ infections were correlated with poor response $(\mathrm{P}=0.008)$.

Univariate Cox regression analysis showed partial immunoparesis, ECOG-PS, NT-proBNP, B2M, hemoglobin, eGFR, LDH and ISS stage III were correlated with first grade $\geq 3$ infections (Table S3). Patients with partial immunoparesis significantly had high risk of early grade $\geq 3$ infections $(\mathrm{P}=0.002$, with 4 months cumulative incidence of $50.0 \%$ vs. $20.0 \%$, Figure $1 A$ ). Multivariate Cox regression analysis revealed partial immunoparesis as an independent significant prognostic factor for first grade $\geq 3$ infections [odds ratio $(\mathrm{OR})=3.048 ; 95 \%$ confidence interval (CI): 1.429-6.504; $\mathrm{P}=0.004]$ of ECOP-PS, NT-proBNP and hemoglobin (Table 3).

In our study, high and low risk defined by the predictive model built by Dumontet et al. (10) showed significantly different rates of infection $(\mathrm{P}=0.001$, with 4 months cumulative incidence of $50.7 \%$ vs. $22.0 \%$, Figure $1 B$ ). To found out whether partial immunoparesis could improve the risk model of Dumontet et al. (10), we explored the prognostic value of partial immunoparesis in low/ high risk groups defined by Dumontet et al. (10). Partial immunoparesis could identify a subgroup of patients with higher infection risk in the high risk group defined by Dumontet et al. (10) $(\mathrm{P}=0.037$, with 4 months cumulative incidence of $57.9 \%$ vs. $25.0 \%$, Figure $1 C$ ). However, partial immunoparesis failed to separate the low risk group defined by Dumontet et al. (10) into two subgroups ( $\mathrm{P}=0.415$, with 4 months cumulative incidence of $28.6 \%$ vs. $17.2 \%$, Figure 1D).

\section{Discussion}

Partial immunoparesis had been shown to correlate with inferior clinical features and outcomes in MM patients (13-15). However, the correlation between partial immunoparesis and early infections in MM remained unknown. In this study, we retrospectively explored the impact of partial immunoparesis on the early infections in patients with MM. Our data showed that partial immunoparesis at diagnosis was related to early grade $\geq 3$ infections.

In our study, immunoparesis was observed in $86 \%$ patients of patients and partial immunoparesis in $63 \%$ patients. Similar to our study, previous studies showed that immunoparesis could be detected in $84-94 \%$ patients and partial immunoparesis could be detected in $65-81 \%$ patients (13-15,24). Until now, studies about partial immunoparesis were rare. In our study, partial immunoparesis was 
Table 1 Baseline patient characteristics according to partial immunoparesis at diagnosis

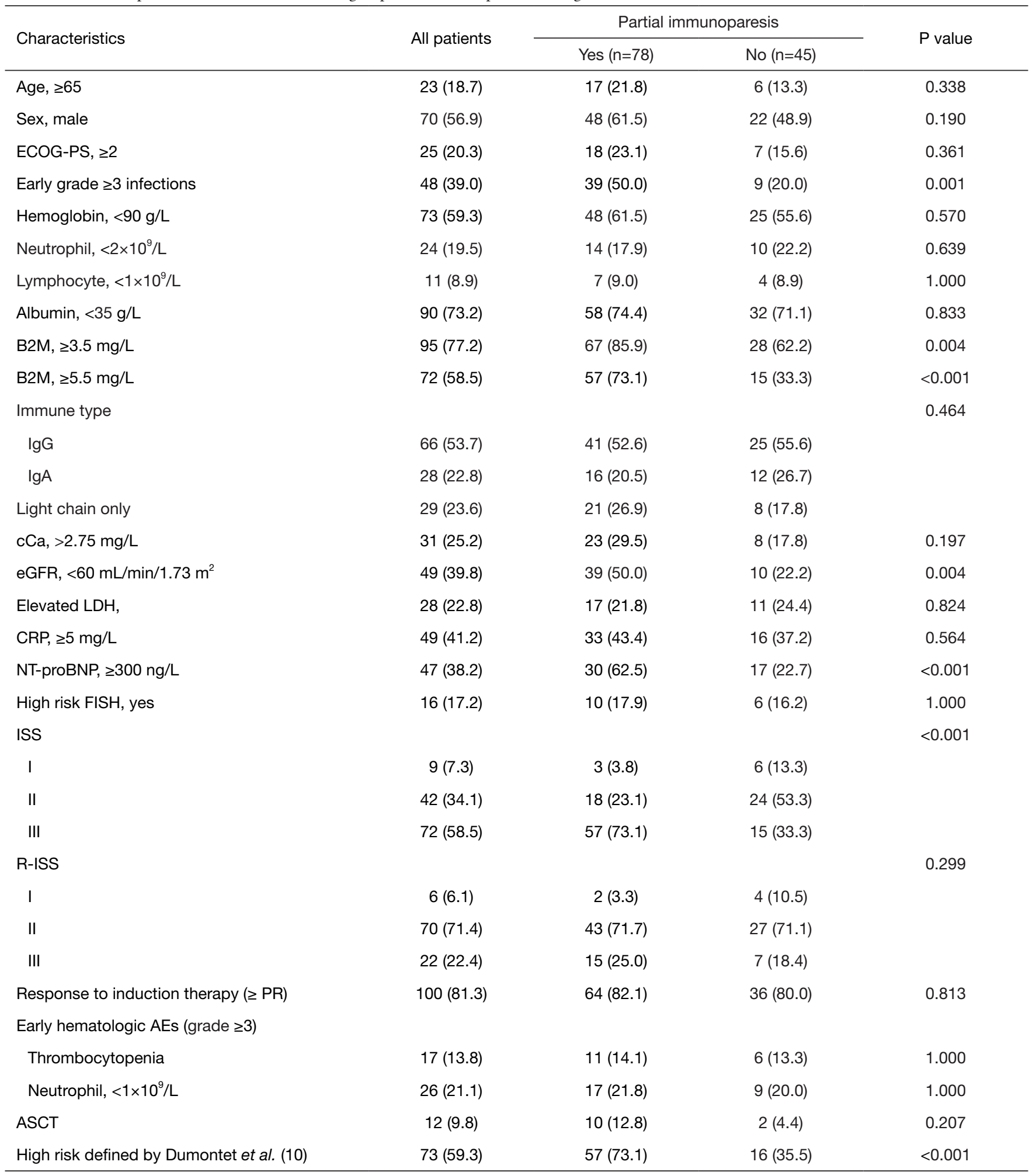

Number (\%). ECOG-PS, Eastern Cooperative Oncology Group-Performance Status; B2M, beta-2-microglobulin; IgG, immunoglobulin G; IgA immunoglobulin A; cCa, corrected calcium; eGFR, estimated glomerular filtration rate; LDH, lactate dehydrogenase; CRP, C-reactive protein; NT-proBNP, N-aimo terminal fragment of the B-type brain natriuretic peptide; FISH, fuorescence in situ hybridization; ISS, international staging system; R-ISS, revised ISS; PR, partly response; AEs, adverse events; ASCT, autologous stem cell transplant. 
Table 2 Early grade $\geq 3$ infections and grade $\geq 3$ neutropenia at the time of infection

\begin{tabular}{lc}
\hline Types & Number (\%) \\
\hline MDI & $2(4.2)$ \\
Pneumonia & $1(2.1)$ \\
Acinetobacter baumannii & $1(2.1)$ \\
Staphylococcus haemolyticus & $2(4.2)$ \\
Septicemia & $1(2.1)$ \\
Streptococcus bovis type II & $1(2.1)$ \\
Herpes zoster & \\
CDI & $32(66.7)$ \\
Pneumonia & $22(45.8)$ \\
Bacterial & $4(8.3)$ \\
Fungal & $6(12.5)$ \\
Bacterial and fungal & $2(4.1)$ \\
Colitis & $2(4.1)$ \\
Urinary tract infection & $8(16.7)$ \\
FUO & $13(27.1)$ \\
Neutrophil <1×10 $/$ L at the time of infection & CDI, clinical \\
\hline MDI, microbiologically documented infection &
\end{tabular}

associated with elevated B2M, decreased eGFR and high ISS scores and was not associated with treatment response, which were similar to a pervious large cohort study (13). Our results were also consistent with a previous study in that the majority of infections occurred during the first 4 months of treatments (10). Most ASCT events were performed after the first 4 months, thus ASCT wasn't a risk factor for early infections ( $\mathrm{P}=1.000$, data not shown) in this study.

Currently, two risk scoring systems had been developed to separate patients into high- and low-risk groups for early grade $\geq 3$ infections $(10,11)$. Dumontet et al. (10) found ECOG-PS, serum B2M, LDH and hemoglobin levels were independent significant factor in predicting early grade $\geq 3$ infections. However, the study didn't take immunoparesis or partial immunoparesis into consideration. A larger study of 5,826 UK myeloma trial patients showed immunoparesis had no effect on survival in the first few months (25) and several studies $(11,26,27)$ also found there was no association between infections and immunoparesis, but they didn't take partial immunoparesis or levels of polyclonal Igs into consideration. Igs and plasma cells played an important role in the protection against infections, but the prognostic value of partial immunoparesis in infections remained unknown. In our study, patients with partial immunoparesis at diagnosis had significantly high risk of infections. Univariate and multivariate Cox regression analyses suggested the prognostic value of partial immunoparesis in infections was independent of ECOGPS, serum B2M, LDH and hemoglobin. We also found the partial immunoparesis improved the risk stratification of the predict model built by Dumontet et al. (10) in MM patients. In our study, MMIRI wasn't taken into analysis due to lacking of some parameters. Response to treatment and neutropenia were adverse factors that contributes to infections $(11,28)$. Table 1 showed that the distribution of these two factors had no significant difference between the two groups separated by partial immunoparesis. A pervious large cohort study also showed partial immunoparesis wasn't associated with response (13). As a result, partial immunoparesis may be considered as an independent poor prognostic factor for early grade $\geq 3$ infections in newly diagnosed MM patients.

Neutropenia was associated with infections in $M M$ $(11,29)$. However, in this study we didn't observe significant correlation between grade $\geq 3$ neutropenia and grade $\geq 3$ infections $(\mathrm{P}=0.249)$ (Table $\mathrm{S} 2)$. This result was similar to a previous study (23). Dumontet et al. (10) also found nearly $75 \%$ of all grade $\geq 3$ infections occurred in the absence of neutropenia in MM patients. We believed this was at least partly due to the administration of recombinant human granulocyte colony-stimulating factors (rhG-CSF), which is common in the treatment of neutropenia. In this study, all patients with grade $\geq 3$ neutropenia received rhG-CSF, which reduced the duration and severity of neutropenia $(30,31)$, thus decreased the significance of correlation between neutropenia and infections.

This study found NT-proBNP was related with early grade $\geq 3$ infections. NT-proBNP was a frailty parameter and was associated with disease severity in MM $(32,33)$. Anemia, renal and cardiac impairments due to deposition of monoclonal light chains were common in MM patients (34). These complications contribute to both high level of NTproBNP (35-40) and infections (41-43), which underlines the plausibility of the correlation between NT-proBNP and risk of infection in MM patients.

We also found the severity of $\operatorname{IgG}$ and $\operatorname{IgM}$ suppression 

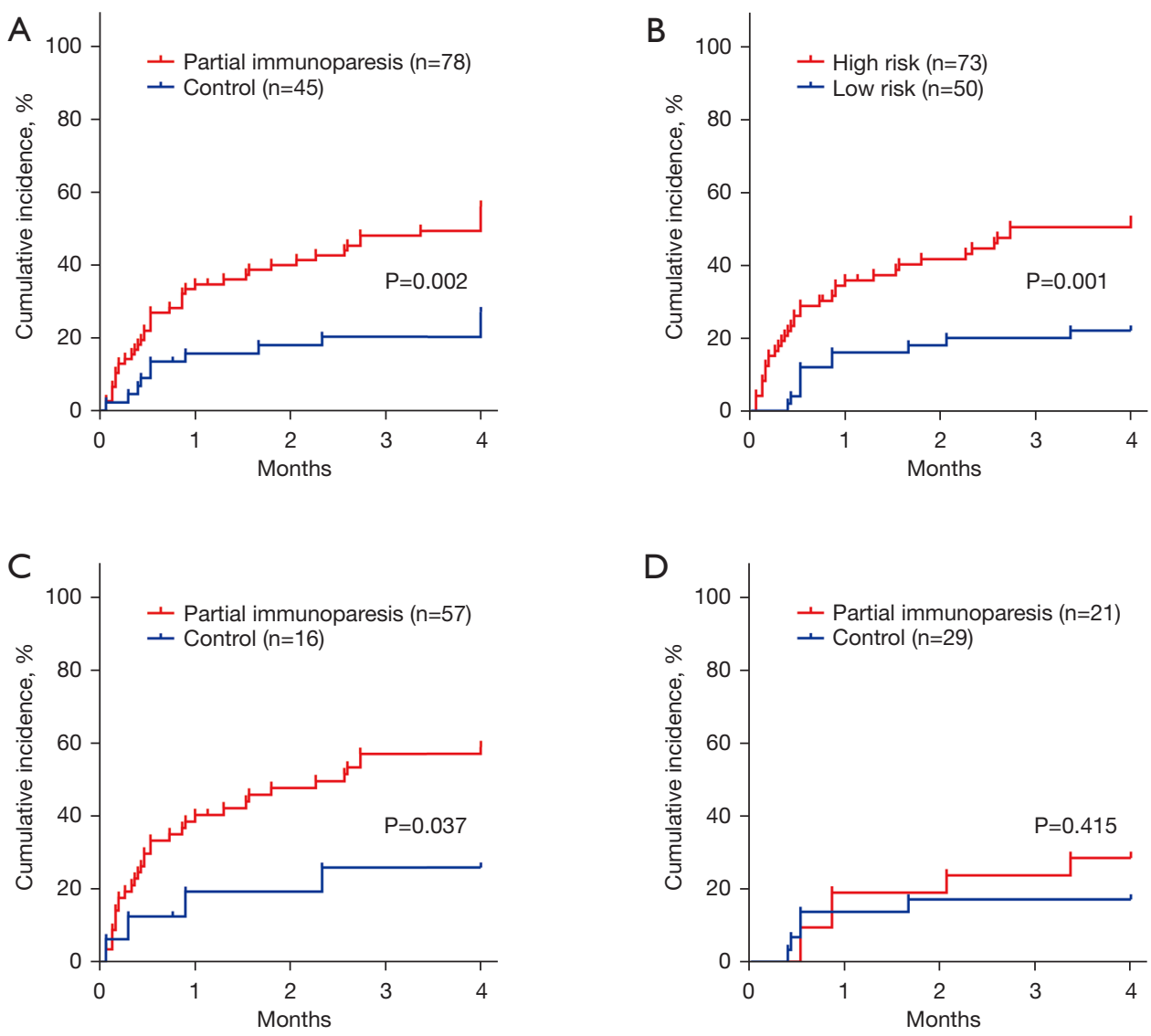

Figure 1 Cumulative incidence of first early grade $\geq 3$ infections according to partial immunoparesis. Cumulative incidence of first early grade $\geq 3$ infections according to partial immunoparesis in the entire group (A), risk groups defined by Dumontet et al. (10) (B), high (C) and low (D) risk group defined by Dumontet et al. (10).

Table 3 Multivariate Cox regression analysis for grade $\geq 3$ infections

\begin{tabular}{llll}
\hline Various & OR & $95 \% \mathrm{Cl}$ & $\mathrm{P}$ value \\
\hline ECOG-PS, $\geq 2$ & 2.754 & $1.457-5.207$ & 0.002 \\
NT-proBNP, $\geq 300 \mathrm{ng} / \mathrm{L}$ & 2.766 & $1.369-5.591$ & 0.005 \\
Partial immunoparesis & 3.048 & $1.429-6.504$ & 0.004 \\
eGFR, $<60 \mathrm{~mL} / \mathrm{min} / 1.73 \mathrm{~m}^{2}$ & 0.916 & $0.381-2.201$ & 0.844 \\
B2M, $\geq 5.5 \mathrm{mg} / \mathrm{L}$ & 0.698 & $0.281-1.731$ & 0.438 \\
Elevated LDH & 1.402 & $0.721-2.729$ & 0.319 \\
Hemoglobin, $<90 \mathrm{~g} / \mathrm{L}$ & 2.449 & $1.185-5.063$ & 0.016 \\
\hline
\end{tabular}

OR, odds ratio; Cl, confidence interval; ECOG-PS, Eastern Cooperative Oncology Group-Performance Status; NT-proBNP, N-aimo terminal fragment of the B-type brain natriuretic peptide; eGFR, estimated glomerular filtration rate; LDH, lactate dehydrogenase; B2M, beta-2-microglobulin. 
was associated with early grade $\geq 3$ infections in IgA $M M$, suppression of IgA was also significantly related to infections in IgG MM. However, no significant association between the severity of immunosuppression was found in light chain only MM. Currently, the cut-off value of severity of immunosuppression was still controversial. Due to the small number of patients in the study, we couldn't make up a solid conclusion.

There is a broad complexity of immunodeficiency in patients with $M M$ and management of infections represents a clinical challenge. Currently, oral administration of antibiotics is commonly taken in routine clinical practice for prevention of infections. A randomized study of 977 patients found all patients were benefit from prophylactic levofloxacin and suggested prophylactic antibiotics for 4 months (44). Decisions of antibiotic prophylaxis depends on the common pathogens in each region and the course of diseases. We hope our study would guide the accurate use of antibiotic prophylaxis and avoid antibiotic abuse. Antimicrobial prophylaxis and immune enhancement strategies such as vaccination were strongly recommended for patients with partial immunoparesis.

It should be noted that this study was a retrospective study with a relatively small number of patients from a single center and antibiotic prophylaxis was not routine used. However, all the included patients were only bortezomib-based regimens, which could deduce the selection bias. Although similar with other recent studies of Chinese MM patients (19-22), the median age at diagnosis was younger than Western people and few receive intensive treatment or ASCT dues to cost and acceptance of ASCT. Our results need to be verified by future studies.

\section{Conclusions}

In summary, we explored the impact of partial immunoparesis on the early infections in patients with MM and found that partial immunoparesis was associated with early grade $\geq 3$ infections. Once we result was confirmed in the prospective study, these patients should receive antibiotic prophylaxis.

\section{Acknowledgments}

Funding: This work was supported by the National Natural Science Foundation of China (grant Nos. 81600165, 81670183) and the Medical Science and Technology Project of Guangdong Province (grant No. A2018120).

\section{Footnote}

Reporting Checklist: The authors have completed the STROBE reporting checklist. Available at https://dx.doi. org/10.21037/tcr-21-1627

Data Sharing Statement: Available at https://dx.doi. org/10.21037/tcr-21-1627

Conflicts of Interest: All authors have completed the ICMJE uniform disclosure form (available at https://dx.doi. org/10.21037/tcr-21-1627). The authors have no conflicts of interest to declare.

Etbical Statement: The authors are accountable for all aspects of the work in ensuring that questions related to the accuracy or integrity of any part of the work are appropriately investigated and resolved. The study was conducted in accordance with the Declaration of Helsinki (as revised in 2013). The current study protocol was approved by the Ethics Committee of Southern Medical University Nanfang Hospital, Guangzhou, China (No. NEFC2020-R090). All patients gave written informed consent themselves prior to treatment allowing the use of their medical records for medical research.

Open Access Statement: This is an Open Access article distributed in accordance with the Creative Commons Attribution-NonCommercial-NoDerivs 4.0 International License (CC BY-NC-ND 4.0), which permits the noncommercial replication and distribution of the article with the strict proviso that no changes or edits are made and the original work is properly cited (including links to both the formal publication through the relevant DOI and the license). See: https://creativecommons.org/licenses/by-nc-nd/4.0/.

\section{References}

1. Kumar SK, Rajkumar SV, Dispenzieri A, et al. Improved survival in multiple myeloma and the impact of novel therapies. Blood 2008;111:2516-20.

2. Hsu P, Lin TW, Gau JP, et al. Risk of Early Mortality in Patients With Newly Diagnosed Multiple Myeloma. Medicine (Baltimore) 2015;94:e2305.

3. Augustson BM, Begum G, Dunn JA, et al. Early mortality after diagnosis of multiple myeloma: analysis of patients entered onto the United kingdom Medical Research Council trials between 1980 and 2002-Medical Research 
Council Adult Leukaemia Working Party. J Clin Oncol 2005;23:9219-26.

4. Kumar S. Risk of early death in multiple myeloma. Clin Adv Hematol Oncol 2012;10:172-4.

5. Kastritis E, Palumbo A, Dimopoulos MA. Treatment of relapsed/refractory multiple myeloma. Semin Hematol 2009;46:143-57.

6. DuVillard L, Guiguet M, Casasnovas RO, et al. Diagnostic value of serum IL-6 level in monoclonal gammopathies. Br J Haematol 1995;89:243-9.

7. Klein B, Zhang XG, Lu ZY, et al. Interleukin-6 in human multiple myeloma. Blood 1995;85:863-72.

8. Bao H, Lu P, Li Y, et al. Triggering of toll-like receptor-4 in human multiple myeloma cells promotes proliferation and alters cell responses to immune and chemotherapy drug attack. Cancer Biol Ther 2011;11:58-67.

9. Bohnhorst J, Rasmussen T, Moen SH, et al. Toll-like receptors mediate proliferation and survival of multiple myeloma cells. Leukemia 2006;20:1138-44.

10. Dumontet C, Hulin C, Dimopoulos MA, et al. A predictive model for risk of early grade $\geq 3$ infection in patients with multiple myeloma not eligible for transplant: analysis of the FIRST trial. Leukemia 2018;32:1404-13.

11. Valkovic T, Gacic V, Nacinovic-Duletic A. Multiple Myeloma Index for Risk of Infection. J Cancer 2018;9:2211-4.

12. Palumbo A, Anderson K. Multiple myeloma. N Engl J Med 2011;364:1046-60.

13. Kastritis E, Zagouri F, Symeonidis A, et al. Preserved levels of uninvolved immunoglobulins are independently associated with favorable outcome in patients with symptomatic multiple myeloma. Leukemia 2014;28:2075-9.

14. Ravi P, Kumar S, Gonsalves W, et al. Changes in uninvolved immunoglobulins during induction therapy for newly diagnosed multiple myeloma. Blood Cancer J 2017;7:e569.

15. Gao W, Li J, Jian Y, et al. Immunoparesis in symptomatic multiple myeloma at diagnosis affects PFS with bortezomib-containing induction therapy, but not ASCT consolidation. Int J Hematol 2019;109:169-74.

16. Rajkumar SV, Dimopoulos MA, Palumbo A, et al. International Myeloma Working Group updated criteria for the diagnosis of multiple myeloma. Lancet Oncol 2014;15:e538-48.

17. Levey AS, Stevens LA, Schmid CH, et al. A new equation to estimate glomerular filtration rate. Ann Intern Med 2009;150:604-12.
18. Palumbo A, Avet-Loiseau H, Oliva S, et al. Revised International Staging System for Multiple Myeloma: A Report From International Myeloma Working Group. J Clin Oncol 2015;33:2863-9.

19. Wang Y, Li Q, Xing S, et al. Clinical Characteristics and Prognosis of MAF Deletion in Chinese Patients With Multiple Myeloma. Clin Lymphoma Myeloma Leuk 2019;19:e545-50.

20. Mei J, Zhai Y, Li H, et al. Prognostic impact of hyperdiploidy in multiple myeloma patients with highrisk cytogenetics: a pilot study in China. J Cancer Res Clin Oncol 2018;144:2263-73.

21. Xiao Z, Yin G, Ni Y, et al. MDR1 polymorphisms affect the outcome of Chinese multiple myeloma patients. Biomed Pharmacother 2017;95:743-8.

22. Li F, Yao FS, Zhu XJ, et al. A randomized phase II, openlabel and multicenter study of combination regimens of bortezomib at two doses by subcutaneous injection for newly diagnosed multiple myeloma patients. J Cancer Res Clin Oncol 2019;145:2343-55.

23. Jung SH, Bae SY, Ahn JS, et al. Lymphocytopenia is associated with an increased risk of severe infections in patients with multiple myeloma treated with bortezomibbased regimens. Int J Hematol 2013;97:382-7.

24. Geng C, Yang G, Wang H, et al. Deep and partial immunoparesis is a poor prognostic factor for newly diagnosed multiple myeloma patients. Leuk Lymphoma 2021;62:883-90.

25. Heaney JLJ, Campbell JP, Iqbal G, et al. Characterisation of immunoparesis in newly diagnosed myeloma and its impact on progression-free and overall survival in both old and recent myeloma trials. Leukemia 2018;32:1727-38.

26. Sørrig R, Klausen TW, Salomo M, et al. Immunoparesis in newly diagnosed Multiple Myeloma patients: Effects on overall survival and progression free survival in the Danish population. PloS One 2017;12:e0188988.

27. Sørrig R, Klausen TW, Salomo M, et al. Risk factors for infections in newly diagnosed Multiple Myeloma patients: A Danish retrospective nationwide cohort study. Eur J Haematol 2019;102:182-90.

28. Perri RT, Hebbel RP, Oken MM. Influence of treatment and response status on infection risk in multiple myeloma. Am J Med 1981;71:935-40.

29. Pratt G, Goodyear O, Moss P. Immunodeficiency and immunotherapy in multiple myeloma. Br J Haematol 2007;138:563-79.

30. Leleu X, Gay F, Flament A, et al. Incidence of neutropenia and use of granulocyte colony-stimulating factors in 
multiple myeloma: is current clinical practice adequate? Ann Hematol 2018;97:387-400.

31. Gianni AM, Bregni M, Siena S, et al. Granulocytemacrophage colony-stimulating factor or granulocyte colony-stimulating factor infusion makes high-dose etoposide a safe outpatient regimen that is effective in lymphoma and myeloma patients. J Clin Oncol 1992;10:1955-62.

32. Milani P, Vincent Rajkumar S, Merlini G, et al. N-terminal fragment of the type-B natriuretic peptide (NT-proBNP) contributes to a simple new frailty score in patients with newly diagnosed multiple myeloma. Am J Hematol 2016;91:1129-34.

33. Pavo N, Cho A, Wurm R, et al. N-terminal B-type natriuretic peptide (NT-proBNP) is associated with disease severity in multiple myeloma. Eur J Clin Invest 2018. [Epub ahead of print].

34. Terpos E, Kleber M, Engelhardt M, et al. European Myeloma Network guidelines for the management of multiple myeloma-related complications. Haematologica 2015;100:1254-66.

35. Wiese S, Breyer T, Dragu A, et al. Gene expression of brain natriuretic peptide in isolated atrial and ventricular human myocardium: influence of angiotensin II and diastolic fiber length. Circulation 2000;102:3074-9.

36. McKie PM, Rodeheffer RJ, Cataliotti A, et al. Aminoterminal pro-B-type natriuretic peptide and B-type natriuretic peptide: biomarkers for mortality in a large community-based cohort free of heart failure. Hypertension 2006;47:874-80.

37. Costello-Boerrigter LC, Boerrigter G, Redfield MM, et

Cite this article as: Huang W, Wei X, Wei Q, Wei Y, Feng R. Partial immunoparesis contributes to risk of early infections in patients with multiple myeloma. Transl Cancer Res 2021;10(12):5258-5266. doi: 10.21037/tcr-21-1627 al. Amino-terminal pro-B-type natriuretic peptide and B-type natriuretic peptide in the general community: determinants and detection of left ventricular dysfunction. J Am Coll Cardiol 2006;47:345-53.

38. Palladini G, Foli A, Milani P, et al. Best use of cardiac biomarkers in patients with $\mathrm{AL}$ amyloidosis and renal failure. Am J Hematol 2012;87:465-71.

39. Khalifeh N, Haider D, Hörl WH. Natriuretic peptides in chronic kidney disease and during renal replacement therapy: an update. J Investig Med 2009;57:33-9.

40. Desai AS, Bibbins-Domingo K, Shlipak MG, et al. Association between anaemia and $\mathrm{N}$-terminal pro-B-type natriuretic peptide (NT-proBNP): findings from the Heart and Soul Study. Eur J Heart Fail 2007;9:886-91.

41. Elom MO, Eyo JE, Okafor FC, et al. Improved infant hemoglobin $(\mathrm{Hb})$ and blood glucose concentrations: The beneficial effect of maternal vitamin A supplementation of malaria-infected mothers in Ebonyi State, Nigeria. Pathog Glob Health 2017;111:45-8.

42. Syed-Ahmed M, Narayanan M. Immune Dysfunction and Risk of Infection in Chronic Kidney Disease. Adv Chronic Kidney Dis 2019;26:8-15.

43. Koul PA, Chaudhari S, Chokhani R, et al. Pneumococcal disease burden from an Indian perspective: Need for its prevention in pulmonology practice. Lung India 2019;36:216-25.

44. Chicca IJ, Heaney JLJ, Iqbal G, et al. Stratifying risk of infection and response to therapy in patients with myeloma: a prognostic study. Southampton: NIHR Journals Library, 2020. 


\section{Supplementary}

Table S1 Early grade $\geq 3$ infections according to severity of suppressed uninvolved immunoglobulins

\begin{tabular}{|c|c|c|c|c|c|c|}
\hline Immune types & $\begin{array}{c}\text { Types of suppressed } \\
\text { uninvolved lgs }\end{array}$ & $\begin{array}{l}\text { Severity of suppressed } \\
\text { uninvolved lgs, \% }\end{array}$ & All patients & Infection, yes & Infection, no & $P$ value \\
\hline \multirow[t]{7}{*}{ Light chain only } & $\lg G$ & $>0$ & 20 [77] & $10[91]$ & 10 [67] & 0.197 \\
\hline & & $>50$ & $5[20]$ & $4[40]$ & $1[7]$ & 0.121 \\
\hline & & $>75$ & 0 & 0 & 0 & - \\
\hline & & $>25$ & 12 [48] & $3[30]$ & $9[60]$ & 0.226 \\
\hline & & $>50$ & $10[40]$ & $3[30]$ & $7[47]$ & 0.678 \\
\hline & & $>75$ & $4[16]$ & $2[20]$ & $2[13]$ & 1.000 \\
\hline & & $>75$ & 0 & 0 & 0 & - \\
\hline \multirow[t]{6}{*}{$\lg A$} & $\lg G$ & $>0$ & 17 [74] & 9 [100] & $8[57]$ & 0.048 \\
\hline & & $>25$ & 15 [65] & 8 [89] & $7[50]$ & 0.086 \\
\hline & & $>50$ & $10[44]$ & 7 [78] & $3[21]$ & 0.013 \\
\hline & & $>75$ & 3 [13] & 2 [22] & $1[7]$ & 0.538 \\
\hline & $\lg M$ & $>0$ & 18 [82] & 9 [100] & 9 [69] & 0.115 \\
\hline & & $>25$ & 12 [57] & 8 [89] & 4 [33] & 0.024 \\
\hline \multirow{5}{*}{$\lg G$} & & $>75$ & $6[9]$ & $3[14]$ & $3[7]$ & 0.406 \\
\hline & $\lg M$ & $>0$ & $51[77]$ & 18 [82] & 33 [75] & 0.757 \\
\hline & & $>25$ & 46 [70] & 17 [77] & 29 [66] & 0.405 \\
\hline & & $>50$ & 34 [52] & 14 [64] & 20 [46] & 0.198 \\
\hline & & $>75$ & 15 [23] & $7[32]$ & $8[18]$ & 0.229 \\
\hline
\end{tabular}

Number [\%]. Ig, immunoglobulin. 
Table S2 Therapeutic regimens, grade $\geq 3$ neutropenia and grade $\geq 3$ infections

\begin{tabular}{lcc}
\hline Various & Infection, no & Infection, yes \\
\hline Therapeutic regimens & $50(67.6)$ & $24(32.4)$ \\
VCD & $9(69.2)$ & $4(30.8)$ \\
PAD & $16(44.4)$ & $20(55.6)$ \\
VDT & & \\
Neutrophil $<1 \times 10^{9} / L$ & $62(63.9)$ & $35(36.1)$ \\
No & $13(50.0)$ & $13(50.0)$ \\
Yes & & \\
Response to induction therapy $(\geq \mathrm{PR})$ & $67(67.0)$ & $33(33.0)$ \\
Yes & $8(34.8)$ & $15(65.2)$ \\
No & & 0.056
\end{tabular}

Number (\%). VCD, bortezomib and dexamethasone plus cyclophosphamide; PAD, bortezomib and dexamethasone plus doxorubicin; VDT, bortezomib and dexamethasone plus thalidomide; PR, partly response.

Table S3 Univariate Cox regression analysis for early grade $\geq 3$ infections

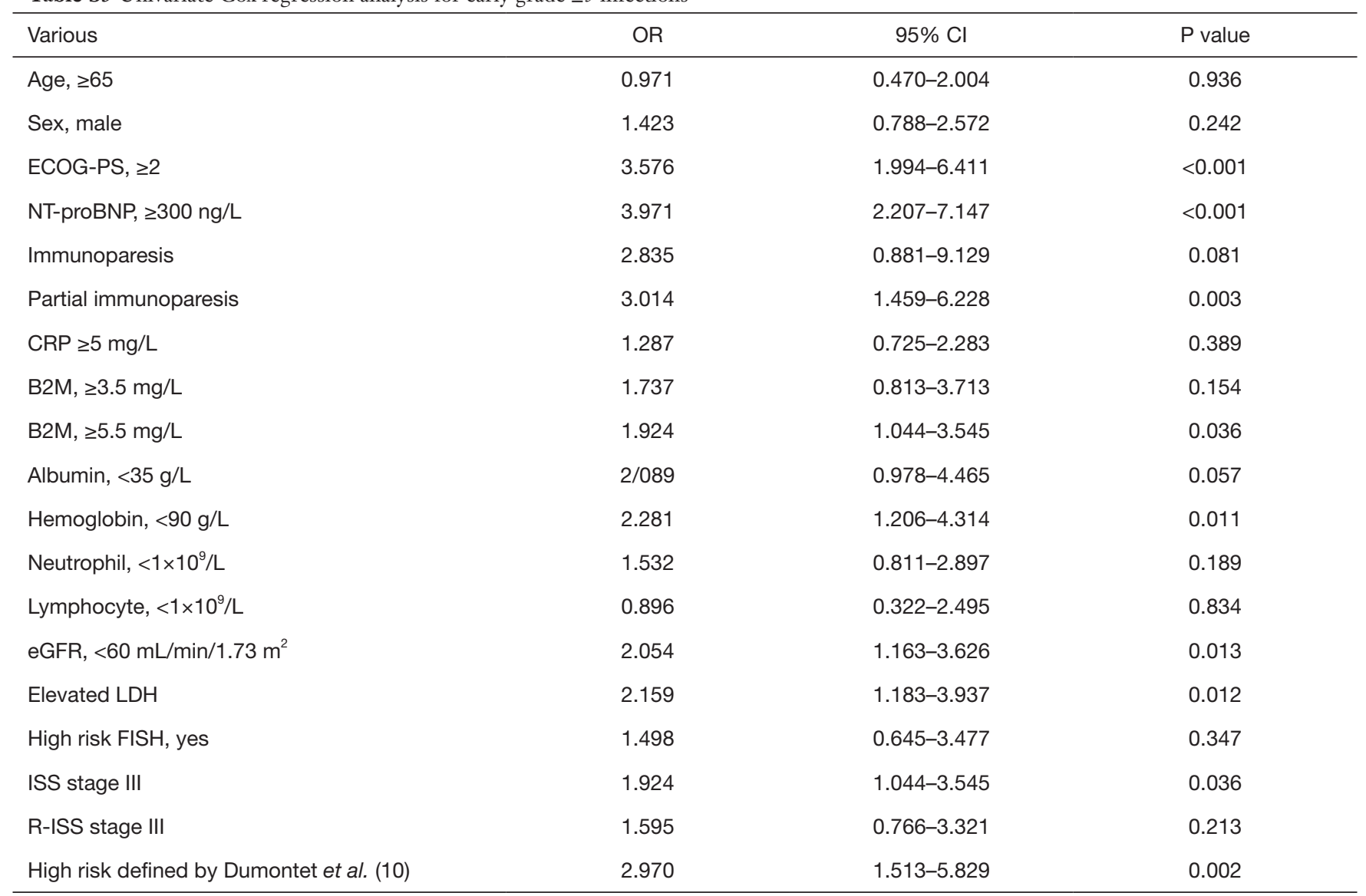

OR, odds ratio; Cl, confidence interval; ECOG-PS, Eastern Cooperative Oncology Group-Performance Status; NT-proBNP, N-aimo terminal fragment of the B-type brain natriuretic peptide; CRP, C-reactive protein; B2M, beta-2-microglobulin; eGFR, estimated glomerular filtration rate; $\mathrm{LDH}$, lactate dehydrogenase; FISH, fuorescence in situ hybridization; ISS, international staging system; R-ISS, revised ISS. 